OPEN ACCESS

Edited by:

Alaa El-Din Hamid Sayed,

Assiut University, Egypt

Reviewed by:

Raju Murugananthkumar,

National Institutes of Health $(\mathrm{N} / \mathrm{H})$,

United States

Sami I. Ali,

National Research Centre, Egypt

*Correspondence:

Kai K. Lie

kli@hi.no;

kaikristoffer.lie@hi.no

${ }^{\dagger}$ Present address:

Pål A. Olsvik,

Faculty of Biosciences and Aquaculture, Nord University,

Bodø, Norway

Specialty section:

This article was submitted to Marine Pollution, a section of the journa

Frontiers in Marine Science

Received: 18 April 2019

Accepted: 13 June 2019

Published: 04 July 2019

Citation:

Lie KK, Meier S, Sørhus E

Edvardsen RB, Karlsen Ø and Olsvik PA (2019) Offshore Crude Oil Disrupts Retinoid Signaling and Eye

Development in Larval Atlantic Haddock. Front. Mar. Sci. 6:368.

doi: 10.3389/fmars.2019.00368

\section{Offshore Crude Oil Disrupts Retinoid Signaling and Eye Development in Larval Atlantic Haddock}

\author{
Kai K. Lie*, Sonnich Meier, Elin Sørhus, Rolf B. Edvardsen, Ørjan Karlsen and
} Pål A. Olsvikt

Institute of Marine Research, Bergen, Norway

The aim of this study was to examine the impact of dispersed crude oil on retinoid metabolism and signaling in developing haddock larvae (Melanogrammus aeglefinus). Retinoids and its active metabolites are involved in the regulation of several developmental processes as cell differentiation, growth and limb patterning. Thus, disruption of retinoid signaling, especially during early developmental stages, may have detrimental effects on the organism. In the present study, crude oil exposure during embryonic development and early larvae development disrupted vitamin A signaling by affecting retinoid levels and genes involved in retinoid metabolism. The disruption of retinoid signaling was also evident when looking at the gene expression pattern at several time-points during and after exposure, demonstrating the complexity and temporal factor of retinoid signaling disruption. Exposure during the embryonic period (pre-hatch) resulted in reduced eye size and increased incidence of abnormal eye morphology. The observed changes in expression of retinoid metabolic genes related to the visual cycle indicates that there is a link between the modulated retinoid levels (alltrans retinoic acid and retinol) and increased incidence of abnormal eye development as a result of crude oil exposure. This is the first study to demonstrate disrupted retinoid signaling in fish following crude oil exposure at environmental relevant levels, giving novel insight in to the mechanism of toxicity.

Keywords: retinoid, contaminant, vitamin A, teleost, development, retinoic acid, crude oil, eye development

\section{INTRODUCTION}

Oil spills, as a consequence of offshore oil production, constitute a threat to the marine environment. The toxicity of crude oil to teleosts and its effects on natural stocks have been thoroughly documented through field and laboratory studies (Hodson, 2017). The recent Deepwater Horizon accident in the Gulf of Mexico in spring 2010 was a strong reminder of the ecological and economical implications of uncontrolled oil discharges on natural fisheries and stocks.

The studies in the aftermath of the Exxon Valdez and the Deepwater Horizon oil spills demonstrated the teratogenic and ultimately lethal effects oil compounds can have on fish (Norcross et al., 1996; Dubansky et al., 2013; Incardona et al., 2013, 2014) The Exxon Valdez oil 

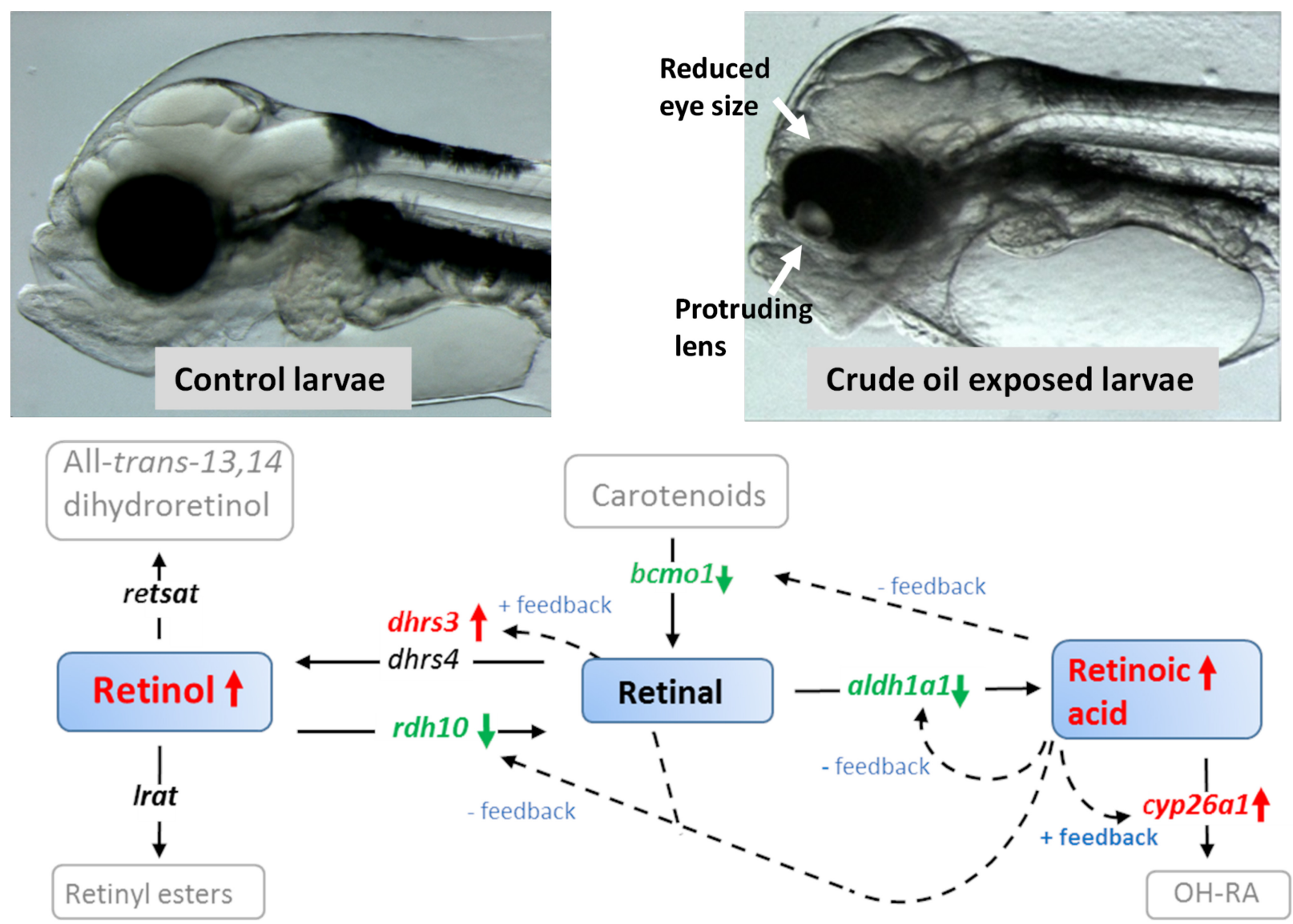

GRAPHICAL ABSTRACT | Crude oil induced disruption of retinoid signaling and eye development. Exposure to crude oil during embryonic development and early larvae development disrupted vitamin A signaling by affecting retinoid levels and genes involved in retinoid metabolism. The disruption of retinoid signaling could be linked to the reduction in eye size and increased incidence of abnormal eye morphology.

spill in Alaska overlapped with the spawning seasons of pink salmon (Oncorhynchus gorbuscha) and Pacific herring (Clupea pallasii). Field and laboratory studies in the aftermath of this disaster disclosed high occurrence of severe developmental abnormalities such as craniofacial deformities, spinal curvature deformities, yolk sack edema, pericardial edema and increased mortality following exposure to crude oil (Carls and Rice, 1990; Norcross et al., 1996; Carls et al., 1999; Incardona et al., 2004, 2014; Carls and Thedinga, 2010; Hicken et al., 2011). The detrimental effects of oil exposure on cardiac function and craniofacial development was recently also demonstrated in Atlantic haddock (Melanogrammus aeglefinus) exposed to crude oil (Sorhus et al., 2016b, 2017). It was proposed that crude oil influence transcription related to calcium signaling, resulting in abnormal development (Sorhus et al., 2017). Single $\mathrm{PAH}$ components and crude oil from various sources have been shown to interrupt ion signaling, which is linked to effects on cardiac development (Incardona et al., 2004, 2009; Brette et al., 2014, 2017; Sorhus et al., 2016b).

In one of our previous studies we observed that exposure to crude oil modulated the expression of several genes related to vitamin A metabolism, such as cytochrome P450, family
26, subfamily A (cyp26a), retinol dehydrogenases and retinoid binding proteins in Atlantic cod (Gadus morhua) larvae (Olsvik et al., 2012). Disturbance of vitamin A homeostasis has been observed in both fish and mammals following exposure to persistent organic pollutants (POPs) (Novák et al., 2007, 2008) and heavy metals (Alsop et al., 2007; Defo et al., 2012) and contaminated sediments. Vitamin A levels have thus been used as markers of contaminant exposure in environmental monitoring. However, the mechanisms behind these disturbances seem to be heterogeneous and remain to be fully elucidated. Many of the observed deformities following crude oil exposure, such as heart, limb and craniofacial deformities, coincide with malformations that may be caused by disruption of vitamin A signaling (Cahu et al., 2003; Haga et al., 2003; Laue et al., 2008; Spoorendonk et al., 2008; D'Aniello and Waxman, 2015). Thus, knowledge on how retinoid signaling is affected by crude oil might give novel insight in to mechanisms of toxicity.

Retinoids is a generic term used for a class of compounds chemically related to vitamin $\mathrm{A}$. The name also reflects its importance for retina function and eye health. The retinoids comprise the three mother compounds, retinol, 
retinal and retinoic acid, and all their metabolic products and isomers. However, retinol (often referred to as vitamin A) is physiologically inert and must be converted to other biological active metabolites of which all-trans retinoic acid (atRA) is regarded as the most potent. During development, retinoids are controlling patterning and limb development [reviewed by Ross et al. (2000)]. In adult organisms, retinoids and their active metabolites are essential for normal cell homeostasis, growth, remodeling, reproduction and vision. Several studies have demonstrated that both excessive and deficient intake of vitamin A can affect development, causing severe morphological abnormalities (Azaïs-Braesco and Pascal, 2000) including heart defects (Colbert, 2002; Pan and Baker, 2007) and bone development in fish (Takeuchi et al., 1998; Mazurais et al., 2008, 2009).

Our knowledge on the effect of environmental contaminants on retinoid signaling and the underlying mechanisms of toxicity are mainly derived from studies using organochloride compounds such as dioxins and polychlorinated biphenyls (PCBs). However, the mechanistic effects might be compoundspecific (Widerak et al., 2006; Benisek et al., 2008; Novák et al., 2008; Benisek et al., 2011). Aryl hydrocarbon receptor (AhR) activation followed by cytochrome P450, family 1, subfamily A (CYP1A) induction is the mode of action for several known toxic compounds such as the organochlorides and polyaromatic hydrocarbons (PAHs). This is also believed to be one of the most important factors disrupting retinoid signaling (Murphy et al., 2007; Berntssen et al., 2015). AhR agonists have been shown to affect retinoid signaling on multiple levels in the retinol metabolic pathway. It is postulated that the activation of CYP1A, which is capable of retinoic acid hydroxylation, increases the metabolization and excretion rate of atRA. This will in turn increase the demand for atRA precursors such as retinol and retinal, and result in depletion of retinoid stores as demonstrated in adult zebrafish (Danio rerio) (Alsop et al., 2007) and Atlantic salmon (Salmo salar) (Berntssen et al., 2016) following benzo(a)pyrene ( $\mathrm{BaP}$ ) exposure. In salmon, this retinoid disruption was accompanied by reduced growth. Other routes of retinoid signaling disruption have also been suggested (Widerak et al., 2006; Benisek et al., 2008, 2011).

The aim of this study was to examine the disruptive impact of dispersed crude oil on vitamin A metabolism and signaling in developing Atlantic haddock larvae. Atlantic haddock were exposed to crude oil during two important periods of organogenesis and growth. The first group (embryo group) was exposed during the embryonic period from 2 to 10 days postfertilization (dpf). The second group (larvae group) was exposed to crude oil from 0 to 18 days post-hatch (dph). Retinoid levels, gene expression, eye size and eye deformities were analyzed in the developing haddock larvae.

\section{MATERIALS AND METHODS}

\section{Fish Husbandry and Exposure}

For detailed procedures on fish collection and breeding, and larval maintenance and exposure, see Sorhus et al. (2016b).
In brief, a wild broodstock population spawning voluntarily in captivity provided the eggs. Eggs were collected from the broodstock tanks and incubated in egg incubators until transfer to exposure tanks. Two days post-fertilization, eggs were transferred to $50 \mathrm{~L}$ circular exposure tanks. At $4 \mathrm{dph}$, the larvae were fed with natural zooplankton (van der Meeren et al., 2014; Karlsen et al., 2015) and the tanks were further supplemented with marine microalgae concentrate (Instant Algae, Nanno 3600, Reed Mariculture Inc., Campbell, CA, United States) until termination of experiments.

The crude oil used in the experiments was an artificially weathered crude oil from the Heidrun oil field in the Norwegian Sea. To generate an oil in water dispersion an oil droplet generation system described elsewhere was used (Nordtug et al., 2011). This system generates an oil dispersion of droplets in the low $\mu \mathrm{m}$ range with a nominal oil load of $26 \mathrm{mg} / \mathrm{L}$ that again are diluted in the exposure tanks. The experimental exposure system consisted of four replicates of three treatments and control: $60 \mu \mathrm{g}$ oil/L (Low dose), $600 \mu \mathrm{g}$ oil/L (High dose), $600 \mu \mathrm{g}$ oil/L for $2.4 \mathrm{~h}$ in a $24 \mathrm{~h}$ period (Pulse dose), and no oil (Control). Water Chemistry and embryo and larvae body burden of PAHs are shown in Sorhus et al. (2016b). The oil doses correspond to water doses of PAHs from 0.7 to $7 \mu \mathrm{g} / \mathrm{L} \Sigma \mathrm{PAH}$.

A schematic view of the exposure periods and sampling time points is presented (Figure 1). In the embryo experiment, the exposure was terminated at $10 \mathrm{dpf}$ ( 8 days of exposure), and all surviving embryos were transferred to new tanks with seawater without crude oil. At $13 \mathrm{dpf}$, 50\% hatching was observed and set to $0 \mathrm{dph}$. In the Larvae experiment, the exposure started at $0 \mathrm{dph}$, and ended at $18 \mathrm{dph}$ (18 days of exposure). Haddock larvae used for retinoids were deprived of food prior to sampling. Sampling time points were chosen from different stages in development in relation to Sorhus et al. (2016a) and in relation to time of exposure and hatching. Since retinoid depletion has previously been shown to be the outcome of PAH exposure in adult fish, we collected samples for retinoid just after hatching (before start feeding) for the embryo exposure study and ca $12 \mathrm{~h}$ post-exposure for the larvae exposure study.

All animal experiments within the study were approved by NARA, the governmental Norwegian Animal Research Authority (http://www.fdu.no/fdu/, reference number 2012/275334-2). All methods were performed in accordance with approved guidelines.

\section{Quantification of Retinoid Metabolites in Fish Larvae Using LC-APCI-MS/MS}

Retinoid analysis was performed by VITAS AS (Norway, Oslo). Pools of about 150 Atlantic haddock larvae (about $150 \mathrm{mg}$ tissue in total) were homogenized with $600 \mu \mathrm{l}$ acetonitrile containing a $\mathrm{C}_{4}$ labeled internal standard $\left(\mathrm{C}_{4}\right.$-atRA) $(n=4$ for all groups except Low $(n=3)$ and Pulse $(n=2)$ group from the Larvae exposure). After thorough homogenizing (30 s), centrifugation $\left(20 \mathrm{~min}, 4000 \mathrm{rpm}, 9^{\circ} \mathrm{C}\right)$, some of the supernatant were transfer to an HPLC vial with insert $(500 \mu \mathrm{l})$ and centrifuged again $(20 \mathrm{~min}$, 
$\left.4000 \mathrm{rpm}, 9^{\circ} \mathrm{C}\right), 10 \mu \mathrm{l}$ of the supernatant was then injected into the HPLC system (Table 1). HPLC was performed with a HP 1200 Liquid Chromatograph (Agilent Technologies, Palo Alta, CA, United States) with a 6460 Triple Quad LC-MS/MS detector using Multiple Reaction Monitoring (MRM). All-trans retinol, all-trans retinal, all-trans retinoic acid, 9-cis retinoic acid and 13-cis retinoic acid were separated on a $25 \mathrm{~cm} \times 3 \mathrm{~mm}, 5 \mu \mathrm{m}$ reversed phase column (Supelco, Suplex PKB-100). The column temperature was $40^{\circ} \mathrm{C}$. Four-point calibration curves were made for the respective retinoids. Table 1 shows the run parameters for HPLC and MS/MS. Due to the amount of sample material needed for the retinoid analysis we were only able to collect material from one timepoint for each of the groups. Also due to the high mortality in the High crude oil embryo group, we did not get enough material to measure the retinoid levels in this group. The larvae were sampled from replica tanks for each group.

\section{Measurements of Eye Size and Deformities}

Digital still micrographs of live larvae were obtained with an Olympus SZX-10 stereo microscope equipped with a $1.2 \mathrm{Mp}$ resolution video camera (Unibrain Fire-I 785c) controlled by BTV Pro 5.4.1 software ${ }^{1}$. Image magnification was calibrated with a stage micrometer. Measurements of eye diameter and body length at $3 \mathrm{dph}$ (embryonic exposure) and $9 \mathrm{dph}$ (larval exposure) were performed using ImageJ (ImageJ 1.48r, National Institutes of Health, Bethesda, MD, United States ${ }^{2}$ ) with the ObjectJ plugin ${ }^{3}$. To correct the eye diameter measurements

${ }^{1}$ www.bensoftware.com

${ }^{2}$ http://rsb.info.nih.gov/ij

${ }^{3}$ https://sils.fnwi.uva.nl/bcb/objectj/index.html
TABLE 1 | Run parameters for LC-APCI-MS/MS retinoid analysis.

\section{HPLC}

Flow rate

Injection volume

$1.2 \mathrm{ml} / \mathrm{min}$

MS/MS source parameters

Polarity

Gas Temp $\left({ }^{\circ} \mathrm{C}\right)$

Positive

APCl Heater

350

Gas flow (1/min)

Nebulizer (psi)

Capillary (V)

APCINeedlePos

Fragmentor

CID

Dwell

MS/MS multiple reaction monitoring

Standard

Retinol

Retinal

13-cis and 9-cis

All-trans retinoic acid

450

6

60

4500

4

130

15

250 (200 for internal standard)

$$
\begin{gathered}
\text { Transition } \\
269.3 \rightarrow 213.1 \\
285.2 \rightarrow 161.0 \\
301.4 \rightarrow 120.9 \\
301.4 \rightarrow 120.9 \\
305.4 \rightarrow 129
\end{gathered}
$$

to compensate for differences in size, the eye diameter was also expressed as \% of standard body length. Developmental abnormalities of the eye were analyzed by observing individual differences in eye shape. Fish were registered and categorized according to four observed phenotypes: (1) no phenotype, normal round shape, (2) bend shape, (3) irregular shape, and (4) protruding lens. The number of analyzed animals
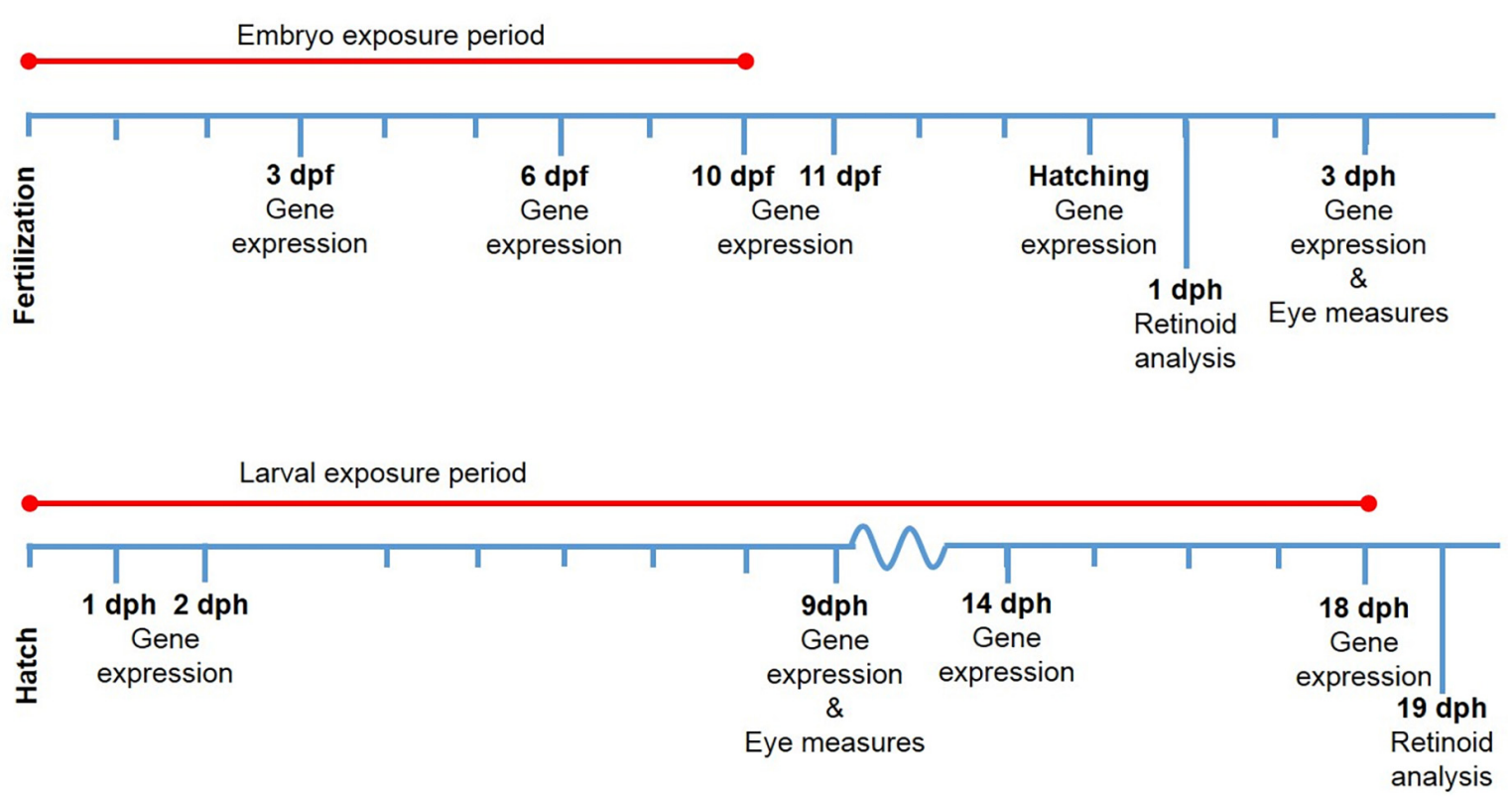

FIGURE 1 | Exposure regimes and sampling points during the two experiments. Sample points are given in days post-fertilization (dpf) and days post-hatch (dph). Analysis performed are given under the sampling point. 
per treatment was 80 (Control, High dose) or 60 (Pulse and Low dose) in the embryonic exposure and 48 for all in the larval exposure.

\section{RNA Extraction and RNA-Seq Analysis}

For detailed procedure for extraction of mRNA, RNA sequencing (RNA-seq), and bioinformatics, see previous studies (Sorhus et al., 2016a, 2017). In brief, pools of live embryos (15-25) and larvae (10) were inspected and imaged under microscope before snap frozen in LN2. Total RNA was isolated from the pools using Trizol reagent (Invitrogen, Carlsbad, CA, United States), followed by a DNase treatment step using TURBO DNA-free kit (Life Technologies Corporation) according to manufacturer's instructions. cDNA library preparation was performed by the Norwegian Sequencing Centre (NSC, Oslo Norway) using the Illumina TruSeq RNA sample preparation kit. Illumina HiSeq2500 platform was used to sequence the paired end libraries. The raw data are available at the Sequence Read Archive (SRA), NCBI (Accession ID: PRJNA328092). The RNA sequencing data were mapped to the coding sequences of the cod genes (Star et al., 2011) using the Bowtie aligner (Langmead et al., 2009) and annotated as described in Sorhus et al. (2016b). Samtools idxstat (Li et al., 2009) was used to extract the number of mapped reads which were then normalized to the total number of mapped sequences.

\section{Statistical Analysis}

The retinoid levels were analyzed using a one-way ANOVA followed by Dunnett's multiple comparison test in GraphPad Prism v 7.02 for Windows (Windows, GraphPad Software, La Jolla, CA, United States). Statistical analysis of RNAseq data was conducted using the Qlucore omics explorer v3.2 software (Qlucore AB, Lund, Sweden). Microsoft ${ }^{\circledR}$ Excel ${ }^{\circledR} 2013$ (Microsoft Corporation, Mountain View, CA, United States) was used to construct a heat map based on fold change values of differentially expressed genes $(p<0.05)$. Statistical difference in eye diameter/body length \% between groups were tested in $\mathrm{R}$ with one-way ANOVA using the Tukey-Kramer multiple comparison test.

\section{RESULTS}

\section{Quantification of Retinoids in Pooled Whole Larvae Homogenates}

While most of the retinoids were in the form of retinal in the $1 \mathrm{dph}$ larvae and very little as retinol (Figure 2), this changed in the $18 \mathrm{dph}$ larvae showing higher levels of retinol. Altered levels of retinoids were observed following continuous and pulse exposure to crude oil during embryogenesis (Figure 2A). Both the Pulse exposure and Low exposure caused significant increase $(p<0.05)$ in retinol levels in the larvae 3 days after exposure had ended and the embryos had been transferred to clean water. Due to high mortality in the High exposure group, samples for retinoid analyses were therefore not available. No difference $(p>0.05)$ was observed in retinal levels between the embryo exposed groups at this point. Both retinol and retinal was significantly modulated compared to Control in larvae exposed after hatching (Figure 2B). While crude oil exposure caused an increase in the retinol levels, the retinal levels were decreased.

In the embryo experiment, retinoic acid levels were increased in the Low exposure group but not in any of the exposed groups in the larvae experiment (Figure 3). Both 13-cis retinoic and 9-cis retinoic acid were below the detection limits of 10 and $2 \mathrm{ng} / \mathrm{g}$, respectively. The detection limit for 13cis retinoic acid was set at $10 \mathrm{ng} / \mathrm{g}$ due to an unidentified interfering component. No differences in total levels of retinoids (retinol + retinal + retinoic acid) were observed between the groups when summing up all analyzed retinoids in the present experiment (Figure 4).
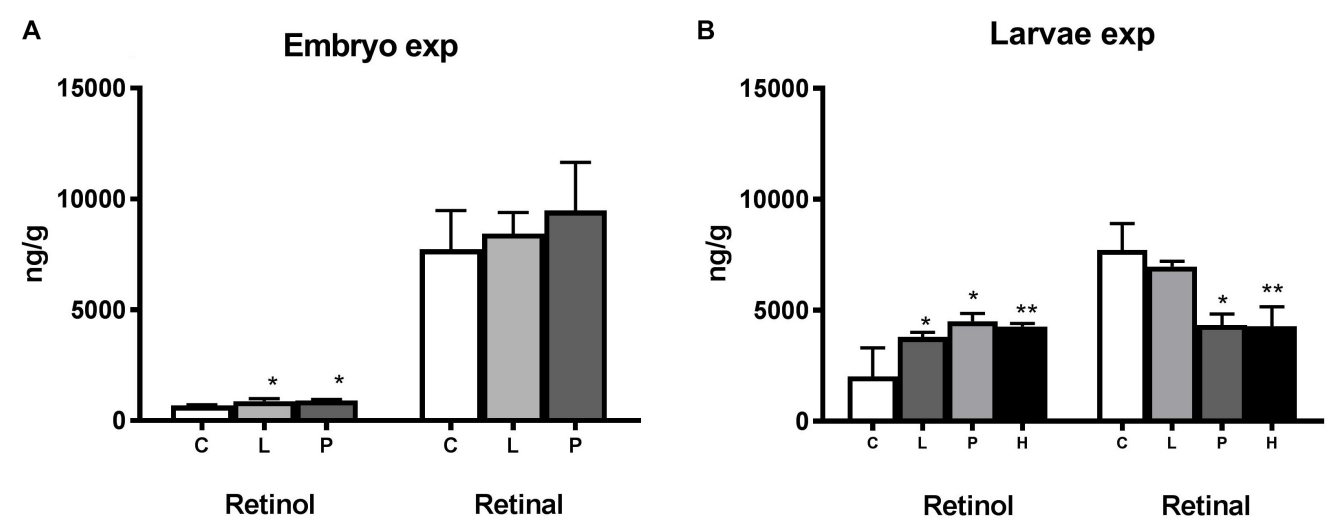

FIGURE 2 | Modulation of retinoid levels in haddock embryo and larvae exposed to crude oil. All-trans retinol (ng retinol/g \pm STD) and all-trans retinal (ng retinal/g \pm STD) levels were measured in (A) 1 day post-hatch (dph) haddock larvae exposed during the embryo stage (2-10 days post-fertilization) and (B) 19 dph larvae exposed during the larvae stage ( $0-18 \mathrm{dph})$. Both embryo and larvae were exposed to different levels of crude oil; Control $(C)$, Pulse $(P)$, Low $(L)$, and High $(H)$. The Low and High group were continuously exposed while the Pulse group was exposed for $2.4 \mathrm{~h}$ in a 24 -h period repeatedly. Asterisk indicate statistical significance $\left({ }^{*} p<0.05,{ }^{* *} p<0.01\right)$. 


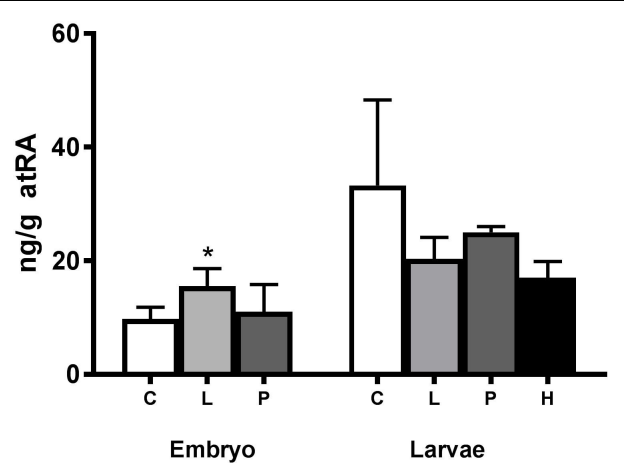

FIGURE 3 | Modulation of all-trans retinoic acid (atRA) in crude oil-exposed haddock larvae. atRA levels (ng atRA/g \pm STD) were measured in 1 day post-hatch (dph) haddock exposed during the embryo stage (2-10 days post-fertilization) and in $19 \mathrm{dph}$ haddock exposed during the larval stage (0-18 dph). Both embryo and larvae were exposed to different levels of crude oil; Control (C), Pulse (P), Low (L), and High (H). The Low and High group were continuously exposed while the Pulse group was exposed for $2.4 \mathrm{~h}$ in a $24-\mathrm{h}$ period repeatedly. Asterisk indicate statistical significance $\left({ }^{*} p<0.05\right)$.

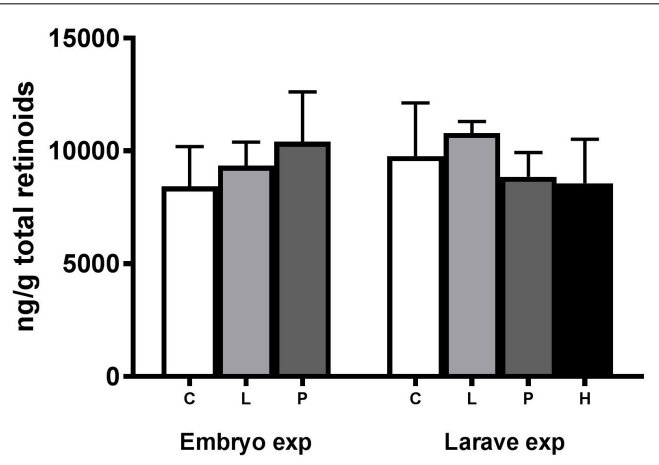

FIGURE 4 | Total amount of retinoids \pm STD (retinol + retinal + retinoic acid) in crude oil-exposed haddock larvae. Retinoids were measured at 1 day post-hatch (dph) haddock exposed during the embryo stage (Embryo) 2-10 days post-fertilization and in 19 dph haddock exposed during the larval stage (Larvae) 0-18 dph. Both embryo and larvae were exposed to different levels of crude oil; Control (C), Pulse (P), Low (L), and High (H). The Low and High group were continuously exposed while the Pulse group was exposed for $2.4 \mathrm{~h}$ in a $24-\mathrm{h}$ period repeatedly.

\section{Expression of Genes Related to Retinoid Metabolism}

Differential expressed genes (DEGs) involved in retinoid metabolism was determined at several time-points during the two experiments. For the embryo experiment, gene expression was measured from $24 \mathrm{~h}$ after exposure start ( $3 \mathrm{dpf}$ ) until $3 \mathrm{dph}, 6$ days after exposure ended. For the larvae exposure, gene expression was measured at $1 \mathrm{dph}, 1$ day after exposure start, until $18 \mathrm{dph}$ at the end of exposure period. The heat map (Figure 5) indicates distinct differences in gene expression profiles between the two exposure regimes (Embryo and Larvae) following $600 \mu \mathrm{g}$ oil/L (High) crude oil exposure. While 51 out of 68 DEG observations were counted as down-regulated in the Embryo experiment, only 5 out of 41 DEG observations showed down-regulation in the Larvae experiment. Very few of the investigated genes were differentially expressed $(p<0.05)$ in the other exposure groups (Supplementary Table S1).

\section{Differential Expression of Genes Related to Retinoid Metabolism Following Embryonic Exposure}

For the embryonic exposure group, none of the investigated genes were differentially expressed the first day following exposure start. Number of genes that were differentially expressed increased as the exposure experiment progressed. Interestingly, the differential expression of several of the genes involved in retinol metabolism and signaling was still evident 6 days after the eggs had been transferred to clean water for hatching and further development. Aldehyde dehydrogenase 1 family, member a1 (aldh1a1) showed even stronger down-regulation as the experiment progressed, peeking several days after transfer to clean water.

There were also clear differences in regulation of several genes during exposure (2-10 dpf) compared to post-exposure $(0-3 \mathrm{dph})$. Although, the exposure was ended at $10 \mathrm{dpf}$, there was a continued exposure at $11 \mathrm{dpf}$ due to remaining oil droplets bound to the eggshell. Genes coding for key enzymes which catalyzes the conversion of retinal to retinol such as dehydrogenase/reductase 3 (dhrs3) was up-regulated post-exposure, while the gene encoding the protein catalyzing the conversion of retinol to retinal, retinol dehydrogenase $10 \mathrm{~b}(r d h 10 b)$, was up-regulated in the during exposure and down-regulated post-exposure. Two possible homologous genes encoding $r d h 10$ have been identified in haddock, of which one rdh10a did not show any differential expression between High dose and control. Two homologs were also found for all-trans-retinol 13,14-reductase (retsat) and lecithin retinol acyltransferase (lrat).

In the High group, cyp26a1 showed down-regulation at 6 and $10 \mathrm{dpf}$ during exposure and up-regulation post-exposure $(0 \mathrm{dph}$ (hatch) and $3 \mathrm{dph})$ in the Low exposure group $(p<0.05)$ (Figure 6). Cyp26a1 tended also to be increased in the High group $(p<0.07)$ post-exposure.

\section{Differential Expression of Genes Related to Retinoid Metabolism Following Larvae Exposure}

Similar as during the embryo exposure, genes related to retinol metabolism such as retsat, lrat, and $r d h 10$ were up-regulated in larvae (Figure 5). Different from during embryo exposure, BetaCarotene 15,15'-Monooxygenase 1 (bcmol) and cyp26al were both up-regulated and no differential expression was observed for aldh1a1.

\section{Effects on Eye Size and Deformities}

Eye diameter (Figures 7A,C) and eye/length ratio (eye diameter divided by the standard length of the larvae) (Figures 7B,D) were measured in 3 dph haddock larvae exposed during the embryonal period (Embryonal exposure) and in $9 \mathrm{dph}$ haddock larvae exposed during the larval stage. Reduced eye diameter was observed for all the exposure groups. However, when the eye diameter was normalized using total length of the larvae, effects of crude oil exposure on eye/length ratio were 


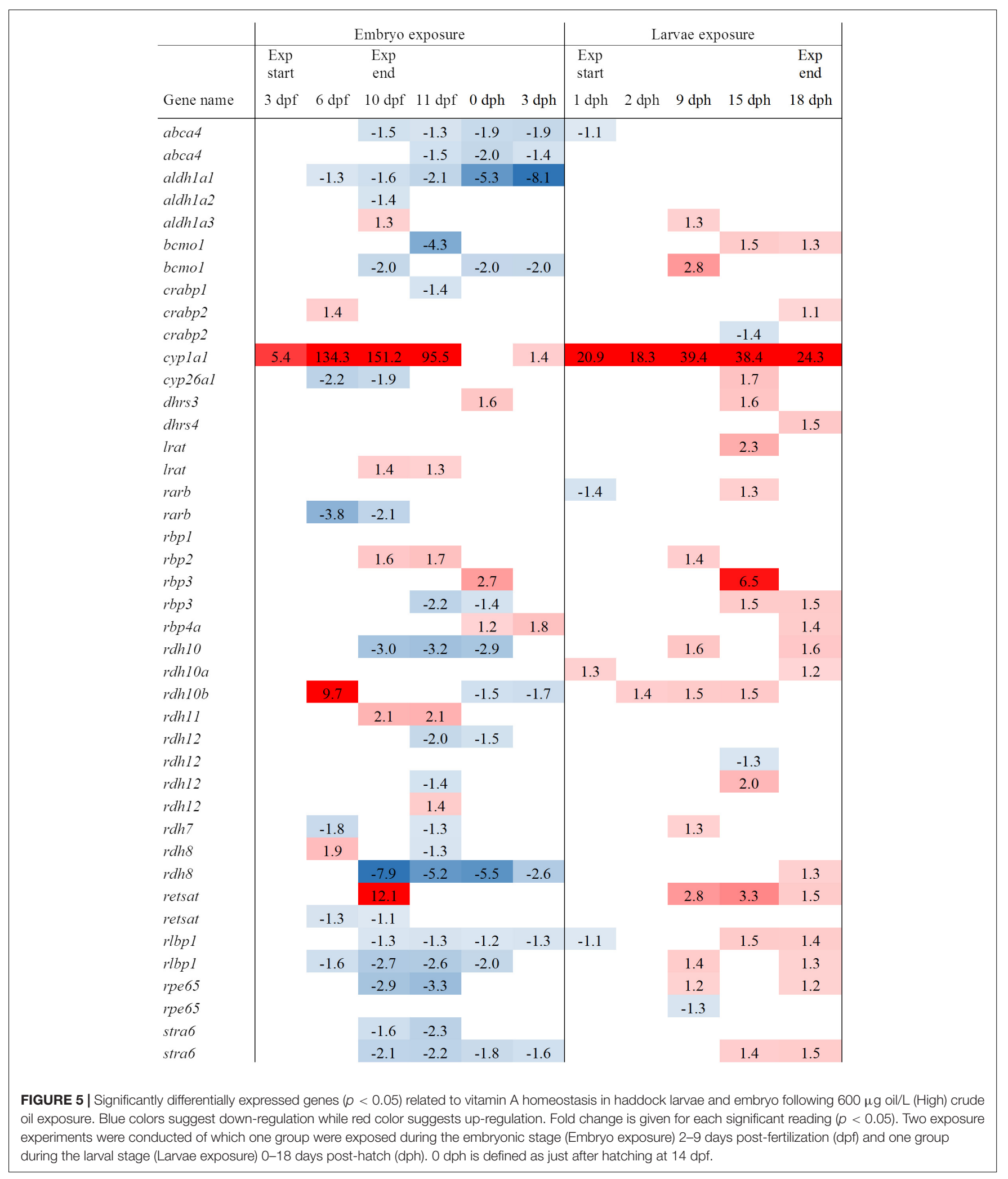

only observed in the Low and Pulse group compared to Control in haddock exposed during the embryonal period. No differences were observed for the 9 dph haddock exposed during larval period. The variation in ratio was also notably larger in the High embryo exposure group compared to the Low and Pulse group. 


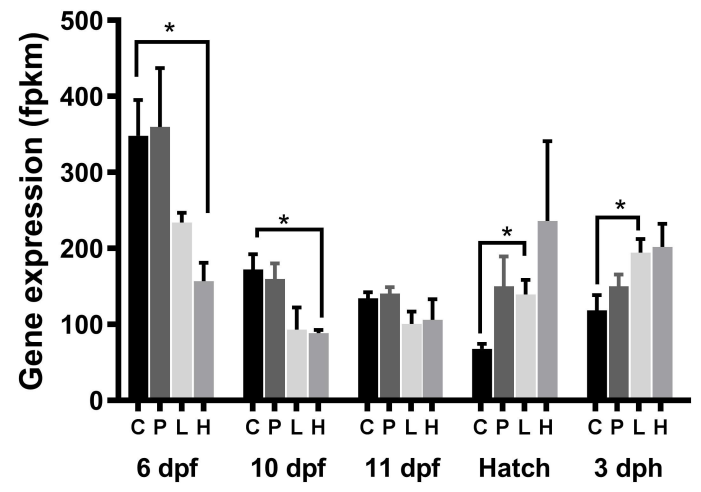

FIGURE 6 | Expression of cyp26a1 in haddock exposed during the embryonic period. Data was derived from the RNA-seq analysis. Both embryo and larvae were exposed to different levels of crude oil; Control $(C)$, Pulse $(P)$, Low $(\mathrm{L})$, and High $(H)$. The Low and High group were continuously exposed while the Pulse group was exposed for $2.4 \mathrm{~h}$ in a $24-\mathrm{h}$ period repeatedly. Asterisk denotes significant differential expression between groups $(p<0.05)$ following Qlucore Omics differential expression analysis.

Presence of eye deformities and irregularities were observed in embryo exposed to crude oil. Three phenotypes were observed in addition to the normal state (no phenotype) (Figure 8 and Table 2). While $95 \%$ of the Control group had no abnormal eye morphology, $59 \%$ of the High and $58 \%$ of the Low group showed abnormal eye morphology. Protruding lens was the most prevalent phenotype in both the High (42\%) and Low group (34\%). The Pulse group seemed less affected.

\section{DISCUSSION}

\section{Disruption of Retinoid Metabolism}

Exposure to off-shore crude oil resulted in a marked disruption of retinoid signaling and metabolism following exposure during both the embryonic stages and during early larvae development in haddock. Increased retinol levels were observed in all exposure groups. In addition, decreased retinal levels were observed in the High exposure larvae group. The present findings suggest that crude oil exposure shunts the retinoid metabolism toward retinol following embryonic and larval exposure (Figures 9A,B). This is further supported by the gene expression data which shows increased dhrs 3 and decreased $r d h 10 b$ pointing toward increased reduction of retinal (Figure 9A). Both enzymes encoded by these genes are key regulators of retinol metabolism acting as important safe guards against excessive levels of retinoic acid.

\section{Exposure During Embryogenesis Caused Post-exposure Effects on Retinoic Acid Signaling}

In addition to increased levels of the parent compound, we observed increased levels of the retinoid metabolite atRA in the haddock exposed during embryonal development. Retinoic acid is regarded as a potent nutrient hormone with teratogenic potential [reviewed by Ross et al. (2000)] and the tissue concentration act as a signal to individual cells modulating gene expression, cell function and limb patterning (Ross et al., 2000; Niederreither et al., 2002; Pan and Baker, 2007). Thus, disruption of atRA signaling can have detrimental effects on the developing embryo in both mammals (Ross et al., 2000) and fish (Takeuchi et al., 1998; Haga et al., 2002, 2003). The disruption of retinoid homeostasis and signaling was also evident when looking at the gene expression data. The increased expression of cyp26a1 at hatch and $3 \mathrm{dph}$ supports the results showing increased atRA levels post-hatch following crude oil exposure during the embryonal period. This key enzyme is directly regulated by atRA through positive feedback mechanism in both fish and mammals (Thatcher and Isoherranen, 2009; Lie and Moren, 2012). The expression patterns of bcmo1, aldh1a1, $d h r s 3$, and $r d h 10 b$ further supports the observed increase in retinoic acid post-exposure (Figure 9A). They are all regulated through feedback loops in order to control the levels of the potent nutria-hormone atRA (Elizondo et al., 2000; Strate et al., 2009; Feng et al., 2010; Lobo et al., 2010). Strict local regulation of atRA is crucial for normal development of both heart and craniofacial structures (Ross et al., 2000). The present results indicate that the feedback machinery is trying to counteract the increased retinoic acid levels post-exposure (Figure 9A). In contrast to the embryo exposure study, no significant changes in atRA levels were observed following exposure during early larval stages. This probably reflects the difference in sensitivity of the embryonic stage vs. the larval stage. In line with this, a recent parallel study focusing on heart and skeletal defects (Sorhus et al., 2017), showed that haddock was more vulnerable to crude oil exposure during the embryonal period compared to the larval period.

\section{Gene Expression Indicate Decreased Retinoic Acid Signaling in Embryos During Exposure}

It was originally hypothesized that an increase in cytochrome P450 enzymes (i.e., CYP1A, CYP1B, and CYP2B) following crude oil exposure, as observed in the present study, could cause increased unspecific atRA hydroxylation with subsequent decrease in atRA levels (Berntssen et al., 2015, 2016). Although we observed an increase in atRA post-exposure rather than a decrease, atRA was not measured during the actual exposure period in the embryo group. However, the down-regulation of cyp26a1 during exposure, indicates reduced atRA levels during the embryonal exposure at 6-10 dpf. This is also supported by the strong up-regulation of $r d h 10 b$ (Figure 9A) and the downregulation of retinoic acid receptor b (rarb), both regulated by retinoic acid (Strate et al., 2009; Topletz et al., 2015; Shabtai et al., 2018). Similar to the present study, cyp26a1 was down-regulated in conjunction with up-regulation of cypla in Atlantic cod larvae exposed to mechanically dispersed crude oil in a previous study [in Supplementary Files, Olsvik et al. (2012)]. Regulation of CYP26 enzymes have been shown to 
A Embryonal exposure, $3 \mathrm{dph}$

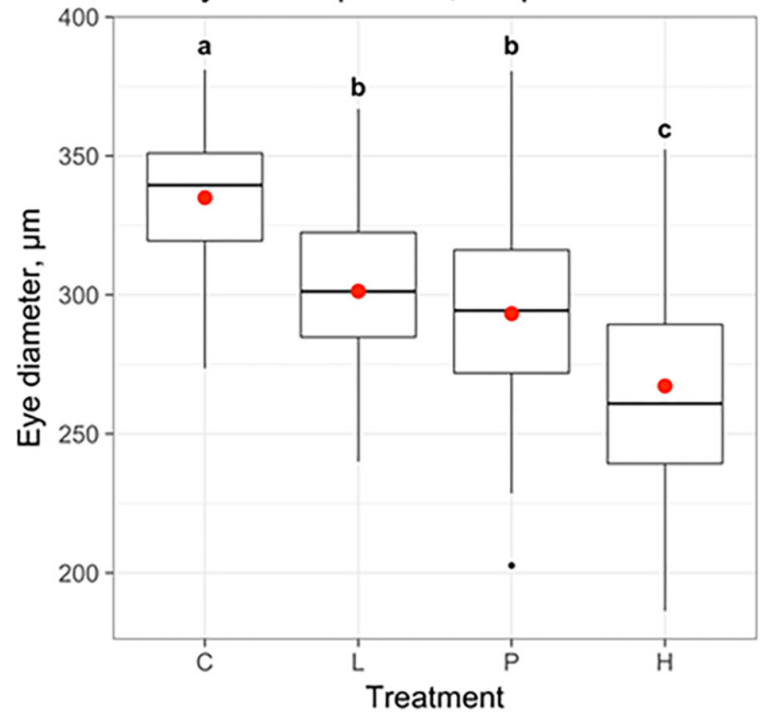

C Larval exposure, $9 \mathrm{dph}$

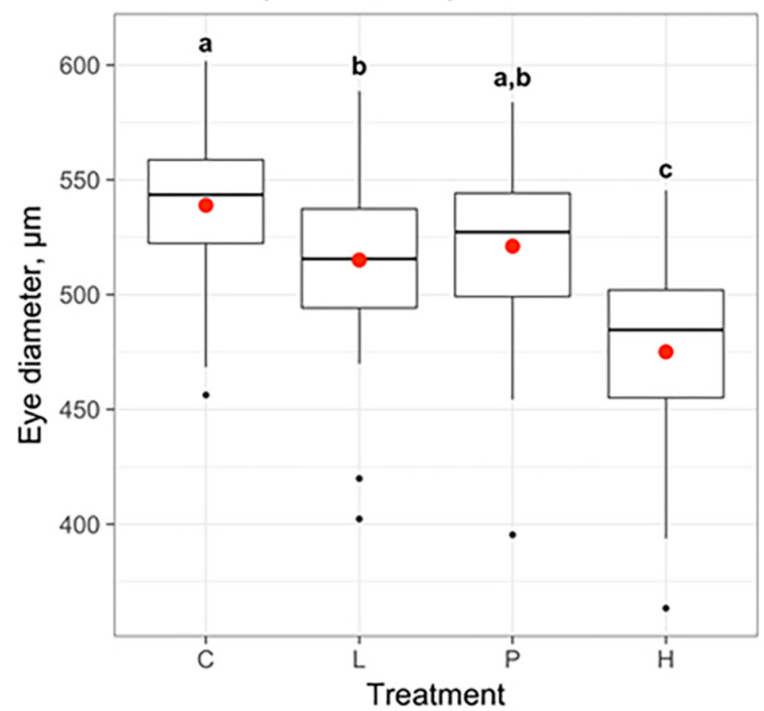

B

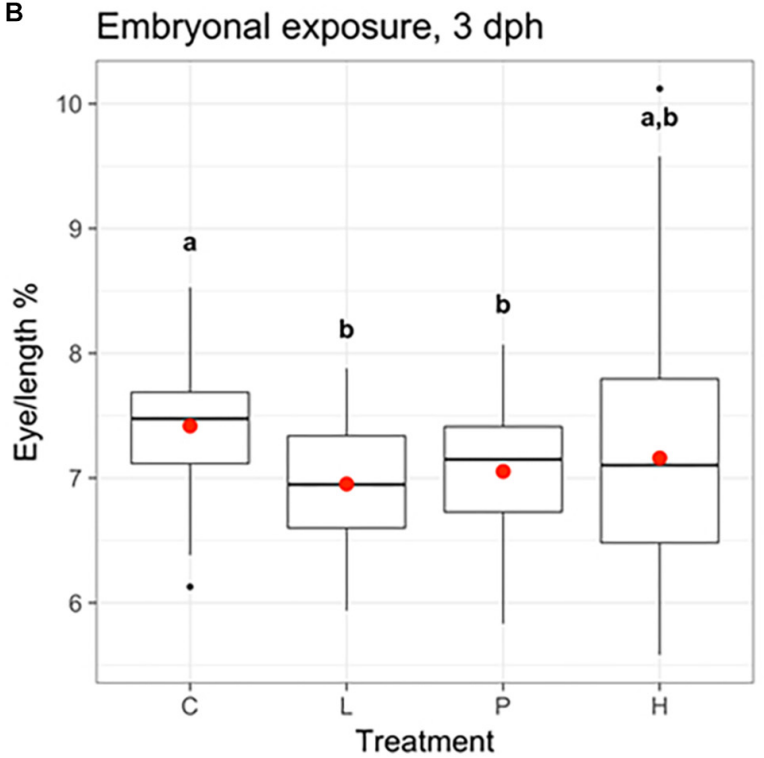

D Larval exposure, $9 \mathrm{dph}$

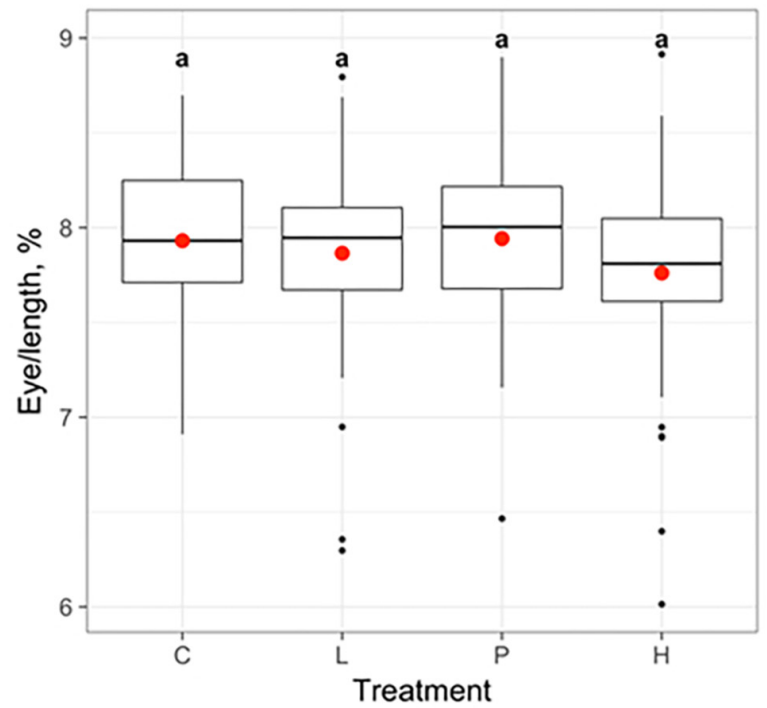

FIGURE 7 | Effects of oil on eye diameter $\mathbf{( A , C )}$ and eye diameter measured as \% of length (Eye/length \%) (B,D) of haddock larvae exposed to crude oil. Eye size was measured at 3 days post-hatch (dph) for the haddock exposed at the embryo stage 2-10 days post-fertilization (A,B) and at 9 dph for the haddock exposed during the larvae stage 0-18 dph (C,D). Both embryo and larvae were exposed to different levels of crude oil; Control (C), Pulse (P), Low (L), and High (H). The Low and High group were continuously exposed while the Pulse group was exposed for $2.4 \mathrm{~h}$ in a 24 -h period repeatedly. Different letters denote statistical significance difference $(p<0.05)$ according to Tukey-Kramer's multiple comparisons test.

be a key mechanism forming the morphogen atRA gradient necessary for limb patterning during embryonic development (White and Schilling, 2008).

\section{Crude Oil Exposure Affect Eye Development in Embryos but Not Larvae}

A reduction in atRA levels with subsequent disruption of retinoid signaling at $6-10 \mathrm{dpf}$ could also be a contributing factor to the observed eye deformities and reduced eye size in the High and Low embryo exposure group of the present study. Retinoids have derived their name from the retina of the eye and plays a key role in both eye development and function (Saari, 2016). The large variation in eye diameter ratio in the High embryo exposure group is most likely related to the gross developmental defects observed in this group (Sorhus et al., 2016b). In the present study, crude oil exposure increased incidence of developmental abnormalities of the eye, 


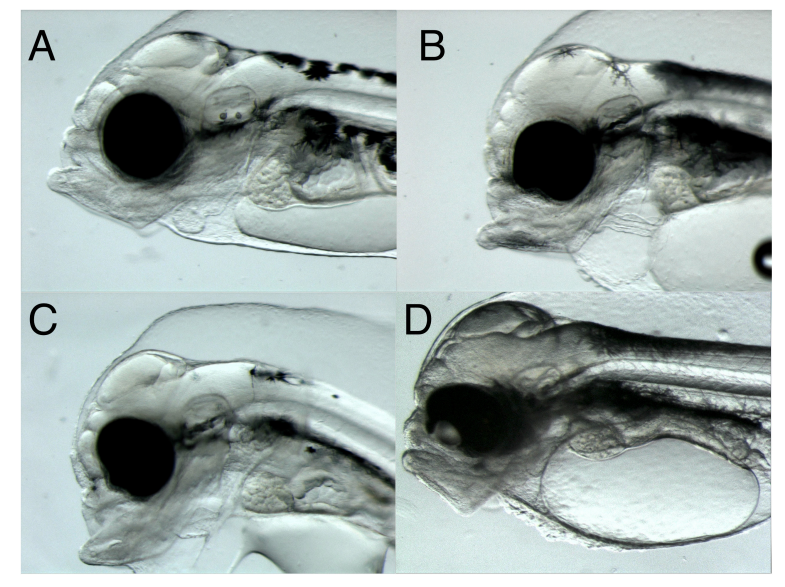

FIGURE 8 | Eye deformities in 3 dph Atlantic haddock following crude oil exposure during the embryonic period. Four phenotypes were observed: (A) no phenotype, normal round shape, (B) bend shape, (C) irregular shape, and (D) protruding lens.

TABLE 2 | Eye abnormalities (\%) registered in 3 dph haddock following embryonic exposure to crude oil.

\begin{tabular}{lcccc}
\hline Treatment & $\begin{array}{c}\text { \% No } \\
\text { phenotype }\end{array}$ & \% Bend & $\begin{array}{c}\% \\
\text { Irregular }\end{array}$ & $\begin{array}{c}\% \\
\text { Protruding } \\
\text { lens }\end{array}$ \\
\hline Control & 95 & 5 & 0 & 0 \\
Low dose & 42 & 17 & 7 & 34 \\
Pulse dose & 63 & 22 & 7 & 8 \\
High dose & 42 & 14 & 3 & 42 \\
\hline
\end{tabular}

especially related to protruding lens in the High and Low embryonal exposure group. Similar effects on eye development has been demonstrated following disruption of atRA production at critical time points during eye development in zebrafish (Le et al., 2012). Two hour inhibition of atRA production induced microphthalmia (reduced eye ball size), retinal abnormalities, irregular eye shape, reduced pigmentation and severe cardiac edema in zebrafish embryos. Similar phenotypes including cardiac edema and craniofacial abnormalities was also observed in crude oil exposed fish from the present study [cardiac edema and craniofacial abnormalities has been presented previously (Sorhus et al., 2016b, 2017)]. Also excess of RA could have damaging effect on eye and limb development (Alsop et al., 2004; Rydeen and Waxman, 2014).

The effects on eye development was also evident from the gene expression data showing effects on eye-related retinoid signaling especially in the embryo group. Genes such as $r d h 8, r d h 10$, ATP binding cassette subfamily A member 4 (abca4), stimulated by retinoic acid (stra6) and Retinal pigment epithelium-specific $65 \mathrm{kDa}$ protein (rpe65), which are crucial for the visual cycle and eye development, were all affected by crude oil exposure. Although many of the retinol dehydrogenase (RDH) enzymes are present in many tissues and cell types, RDH8 expression is limited to the retina (Kiser et al., 2012) Reduction of atRA with subsequent downregulation of genes related to eye development, could be part of the disruptive effects causing the observed eye abnormalities. Especially the downregulation of stra6. STRA6 is a key transporter of which mutation has been previously linked to microphthalmia and heart defects in mammals (Golzio et al., 2007; White et al., 2008). Morpholino knock down of stra6 in zebrafish embryos led to multiple developmental disorders such as microphthalmia, curved body axis, cardiac edema and craniofacial defects (Isken et al., 2008).

Interestingly, the Pulse group had fewer individuals with protruding lens compared to the Low and High group. This coincides with both atRA not being elevated in Pulse and only in the Low group (High was not measured) and that Pulse did not affect cyp26a1 expression. This indicates that Pulse exposure affect the retinoid and eye development differently to continuous dosing and it supports the link between changes in atRA and abnormal eye development following crude oil exposure.

A recent study on Atlantic cod showed that starvation had a big impact on the adverse outcome of crude oil exposure (Hansen et al., 2016). Whether this was caused by impaired vision was not investigated. However, observed effects on eyesight from the present study could have severe consequences for the prey capturing success of the larvae, which in turn would affect the chance of survival for the individual. The Pulse and Low group fish were exposed to $0.7 \mu \mathrm{g} / \mathrm{L}$ PAH. This concentration is environmentally relevant in relation to what have previously been measured following major oil spills like the Exxon Valdez spill in Alaska (Boehm et al., 2007) and the Deepwater Horizon spill in the Gulf of Mexico (Diercks et al., 2010).

\section{No Indication of Retinoid Depletion Following Crude Oil Exposure}

Despite a clear disruption of retinol homeostasis in both groups exposed to crude oil, there were no apparent differences in total retinoid levels between the High, Low and Control when summing up the measured retinol metabolites. This suggests that the strong cypla induction did not cause a depletion of total retinoids as we initially hypothesized, at least not following short term exposure. Long term feeding of adult zebrafish to $150 \mathrm{mg} \mathrm{BaP}$ per $\mathrm{kg}$ feed reduced total retinol levels and retinal levels compared to Control after 100 and 200 days of feeding, respectively (Alsop et al., 2007). A depletion of vitamin A levels was also demonstrated in Atlantic salmon following long term oral $\mathrm{BaP}$ exposure (Berntssen et al., 2016). In both studies the authors observed a negative effect on esterification. Alsop et al. (2007) demonstrated a complete depletion of the esterified retinoids after 260 days of $\mathrm{BaP}$ feeding, while Berntssen et al. (2016) observed decreased lrat expression indicating a reduction in the esterification potential. LRAT together with DGAT convert retinol to retinyl esters. In the present study, lrat was only found to be up-regulated at one point during the embryo and larvae exposure, contrasting the findings in salmon but similar to the effects observed following dioxin exposure of male rats (Rattus norvegicus) (Hoegberg et al., 2003). It should be noted that the retinyl esters, the most common liver storage form, 
A

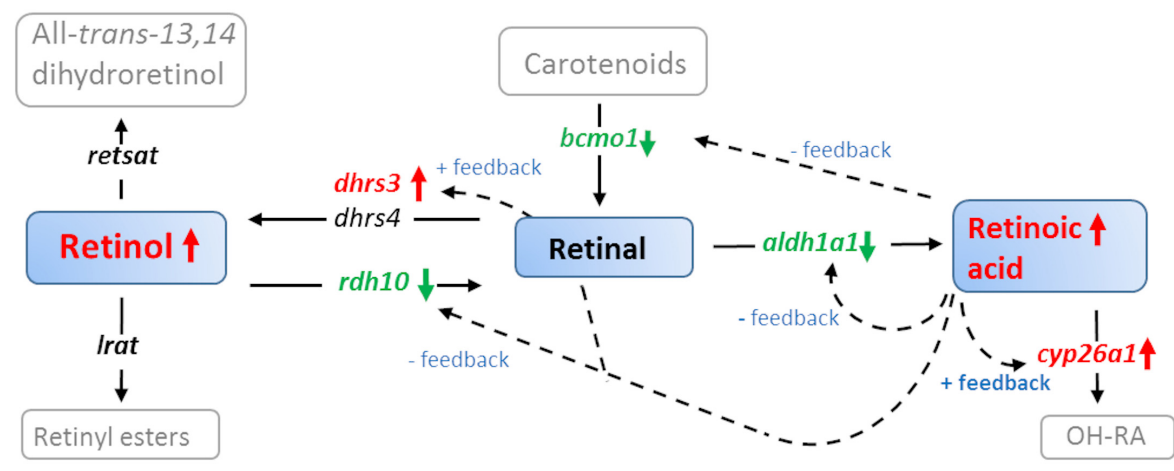

B

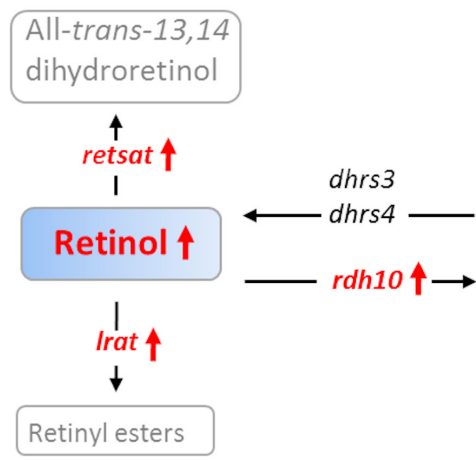

FIGURE 9 | A simplified overview of how crude oil disrupts retinoid signaling in (A) 1 dph Atlantic haddock following embryo exposure (0-10 dpf) and (B) 18 dph haddock following larvae exposure (0-18 dph). Solid colored boxes represent retinoids analyzed in the present paper, open boxes represent retinoids in the pathway but not analyzed in the present paper. Black arrows represent direction of the enzymatic reaction. Red and green arrows represent up and down regulation, respectively of genes coding for retinoid metabolizing enzymes in the present study; all-trans-retinol 13,14-reductase (retsat), lecithin retinol acyltransferase (Irat), short-chain dehydrogenase/reductase 3 (dhrs3), dehydrogenase/reductase 4 (dhrs4), retinol dehydrogenase 10 (rdh10), beta-carotene 15,15-monooxygenase (bcmo1), aldehyde dehydrogenase 1a1 (aldh1a1), cytochrome p450 family 26 subfamily a member 1 (cyp26a1). Colored letters represent differentially regulated genes. Dotted arrows represent feedback mechanisms for cyp26a1 (Thatcher and Isoherranen, 2009), aldh1a1 (Elizondo et al., 2000$),$ bcmo1 (Lobo et al., 2010 ), rdh10 (Strate et al., 2009; Shabtai et al., 2018), dhrs3 (Feng et al., 2010). The general pathway was generated based on Napoli (2016).

were not measured in the present study. However, previous studies have shown that retinyl esters are not detected in fish eggs (Alsop et al., 2007) and the dominating retinoid is retinal (Costaridis et al., 1996; Lubzens et al., 2003; Alsop et al., 2007), in line with our results seen in newly hatched larvae. While the average retinal levels in the Control group were stable between 3 and $18 \mathrm{dph}$, retinol was increasing. Thus, the present data suggests that depletion of retinoids following crude oil exposure is not the biggest concern for cod embryo and larvae but rather the disruption of retinoid signaling.

\section{CONCLUSION}

This study shows that levels of crude oil equivalent to an oil spill is capable of disrupting the vitamin A signaling, affecting gene expression and eye development in developing haddock embryos. It also shows that the mechanisms do not necessarily involve depletion, but rather a direct effect on the vitamin A homeostasis and the active metabolite atRA. The effects on embryonal retinoid signaling persisted several days after exposure. Despite crude oil exposure during embryonic and larval development display similar effects on retinol levels, there is a striking difference in expression of retinoid related genes between the two exposure regimes. The observed effects on eye development may also be associated with disrupted retinol metabolism in the exposed embryos and possibly linked to developmental abnormalities as observed in other studies. We still need more knowledge on the dynamics affecting the retinoic acid and retinol levels in fish larvae during and after crude oil exposure. In addition, the effect on retinyl esters during early development needs clarification.

\section{DATA AVAILABILITY}

Publicly available datasets were analyzed in this study. This data can be found here: https://www.ncbi.nlm.nih.gov/bioproject/ ?term=PRJNA328092.

\section{ETHICS STATEMENT}

All animal experiments within the study were approved by the governmental Norwegian Animal Research Authority (NARA; http://www.fdu.no/fdu/, reference number 2012/2753342). All methods were performed in accordance with approved guidelines. 


\section{AUTHOR CONTRIBUTIONS}

$\mathrm{KL}$ and $\mathrm{PO}$ designed the research questions and wrote the main manuscript. ES and SM contributed to the text. KL, PO, ES, and RE analyzed the data. KL, PO, SM, and ES were actively involved in interpreting the results. KL, PO, SM, ES, and ØK conducted sampling of fish. SM, ES, and $\varnothing \mathrm{K}$ ran the main experiments. SM was primus motor for the project, designing the exposure study, and getting funding. All authors contributed with proofreading of the text.

\section{FUNDING}

This work was financed by the Research Council of Norway (Project Nos. 234367 and 267820, www.forskningsradet.no), the VISTA Foundation (Project No. 6161, www.vista.no), and the Institute of Marine Research, Norway.

\section{REFERENCES}

Alsop, D., Brown, S., and Van Der Kraak, G. (2007). The effects of copper and benzo[a]pyrene on retinoids and reproduction in zebrafish. Aquat. Toxicol. 82, 281-295. doi: 10.1016/j.aquatox.2007. 03.001

Alsop, D. H., Brown, S. B., and Van Der Kraak, G. J. (2004). Dietary retinoic acid induces hindlimb and eye deformities in Xenopus laevis. Environ. Sci. Technol. 38, 6290-6299. doi: 10.1021/es049765n

Azaïs-Braesco, V., and Pascal, G. (2000). Vitamin A in pregnancy: requirements and safety limits. Am. J. Clin. Nutr. 71, 1325s-1333s. doi: 10.1093/ajcn/71.5. $1325 s$

Benisek, M., Blaha, L., and Hilscherova, K. (2008). Interference of PAHs and their $\mathrm{N}$-heterocyclic analogs with signaling of retinoids in vitro. Toxicol. In Vitro 22, 1909-1917. doi: 10.1016/j.tiv.2008.09.009

Benisek, M., Kubincova, P., Blaha, L., and Hilscherova, K. (2011). The effects of PAHs and N-PAHs on retinoid signaling and Oct-4 expression in vitro. Toxicol. Lett. 200, 169-175. doi: 10.1016/j.toxlet.2010.11.011

Berntssen, M. H. G., Ornsrud, R., Hamre, K., and Lie, K. K. (2015). Polyaromatic hydrocarbons in aquafeeds, source, effects and potential implications for vitamin status of farmed fish species: a review. Aquac. Nutr. 21, 257-273. doi: 10.1111/anu.12309

Berntssen, M. H. G., Ornsrud, R., Rasinger, J., Softeland, L., Lock, E. J., Kolas, K., et al. (2016). Dietary vitamin A supplementation ameliorates the effects of polyaromatic hydrocarbons in Atlantic salmon (Salmo salar). Aquat. Toxicol. 175, 171-183. doi: 10.1016/j.aquatox.2016.03.016

Boehm, P. D., Neff, J. M., and Page, D. S. (2007). Assessment of polycyclic aromatic hydrocarbon exposure in the waters of prince william sound after the exxon valdez oil spill: 1989-2005. Mar. Poll. Bull. 54, 339-356. doi: 10.1016/j. marpolbul.2006.11.025

Brette, F., Machado, B., Cros, C., Incardona, J. P., Scholz, N. L., and Block, B. A. (2014). Crude oil impairs cardiac excitation-contraction coupling in fish. Science 343, 772-776. doi: 10.1126/science. 1242747

Brette, F., Shiels, H. A., Galli, G. L. J., Cros, C., Incardona, J. P., Scholz, N. L., et al. (2017). A novel cardiotoxic mechanism for a pervasive global pollutant. Sci. Rep. 7:41476. doi: $10.1038 /$ srep41476

Cahu, C., Infante, J. Z., and Takeuchi, T. (2003). Nutritional components affecting skeletal development in fish larvae. Aquaculture 227, 245-258. doi: 10.1016/ s0044-8486(03)00507-6

Carls, M. G., and Rice, S. D. (1990). Abnormal-development and growth reductions of pollock Theragra chalcogramma embryos exposed to water-soluble fractions of oil. Fish. Bull. 88, 29-37.

Carls, M. G., Rice, S. D., and Hose, J. E. (1999). Sensitivity of fish embryos to weathered crude oil: Part I. Low-level exposure during incubation causes

\section{ACKNOWLEDGMENTS}

We would like to acknowledge Michal Rejmer and Domagoj Maksan for breeding and management of the fish.

\section{SUPPLEMENTARY MATERIAL}

The Supplementary Material for this article can be found online at: https://www.frontiersin.org/articles/10.3389/fmars. 2019.00368/full\#supplementary-material

TABLE S1 | Gene expression related to vitamin A homeostasis in haddock larvae and embryo at several time points during development following High, Low and Pulse crude oil exposure. Experiments were conducted of which one group were exposed during the embryonic stage (Embryo exposure) 2-9 days post-fertilization (dpf) and one group during the larval stage (Larvae exposure) 0-18 days post-hatch (dph).

malformations, genetic damage, and mortality in larval Pacific herring (Clupea pallasi). Environ. Toxicol. Chem. 18, 481-493.

Carls, M. G., and Thedinga, J. F. (2010). Exposure of pink salmon embryos to dissolved polynuclear aromatic hydrocarbons delays development, prolonging vulnerability to mechanical damage. Mar. Environ. Res. 69, 318-325. doi: 10. 1016/j.marenvres.2009.12.006

Colbert, M. C. (2002). Retinoids and cardiovascular developmental defects. Cardiovasc. Toxicol. 2, 25-39.

Costaridis, P., Horton, C., Zeitlinger, J., Holder, N., and Maden, M. (1996). Endogenous retinoids in the zebrafish embryo and adult. Dev. Dyn. 205, 41-51. doi: 10.1002/(sici)1097-0177(199601)205:1<41::aid-aja4>3.0.co;2-5

D'Aniello, E., and Waxman, J. S. (2015). Input overload: contributions of retinoic acid signaling feedback mechanisms to heart development and teratogenesis. Dev. Dyn. 244, 513-523. doi: 10.1002/dvdy.24232

Defo, M. A., Pierron, F., Spear, P. A., Bernatchez, L., Campbell, P. G., and Couture, P. (2012). Evidence for metabolic imbalance of vitamin A2 in wild fish chronically exposed to metals. Ecotoxicol. Environ. Saf. 85, 88-95. doi: 10.1016/j.ecoenv.2012.08.017

Diercks, A. R., Highsmith, R. C., Asper, V. L., Joung, D. J., Zhou, Z. Z., Guo, L. D., et al. (2010). Characterization of subsurface polycyclic aromatic hydrocarbons at the deepwater horizon site. Geophys. Res. Lett. 37:L20602.

Dubansky, B., Whitehead, A., Miller, J. T., Rice, C. D., and Galvez, F. (2013). Multitissue molecular, genomic, and developmental effects of the deepwater horizon oil spill on resident gulf killifish (Fundulus grandis). Environ. Sci. Technol. 47, 5074-5082. doi: 10.1021/es400458p

Elizondo, G., Corchero, J., Sterneck, E., and Gonzalez, F. J. (2000). Feedback inhibition of the retinaldehyde dehydrogenase gene ALDH1 by retinoic acid through retinoic acid receptor A and CCAAT/enhancer-binding protein beta. J. Biol. Chem. 275, 39747-39753. doi: 10.1074/jbc.m004987200

Feng, L., Hernandez, R. E., Waxman, J. S., Yelon, D., and Moens, C. B. (2010). Dhrs3a regulates retinoic acid biosynthesis through a feedback inhibition mechanism. Dev. Biol. 338, 1-14. doi: 10.1016/j.ydbio.2009. 10.029

Golzio, C., Martinovic-Bouriel, J., Thomas, S., Mougou-Zrelli, S., GrattaglianoBessiere, B., Bonniere, M., et al. (2007). Matthew-wood syndrome is caused by truncating mutations in the retinol-binding protein receptor gene STRA6. Am. J. Hum. Genet. 80, 1179-1187. doi: 10.1086/518177

Haga, Y., Suzuki, T., Kagechika, H., and Takeuchi, T. (2003). A retinoic acid receptor-selective agonist causes jaw deformity in the Japanese flounder, Paralichthys olivaceus. Aquaculture 221, 381-392. doi: 10.1016/s0044-8486(03) 00076-0

Haga, Y., Takeuchi, T., and Seikai, T. (2002). Influence of all-trans retinoic acid on pigmentation and skeletal formation in larval Japanese flounder. Fish. Sci. 68, 560-570. doi: 10.1046/j.1444-2906.2002.00462.x 
Hansen, B. H., Lie, K. K., Storseth, T. R., Nordtug, T., Altin, D., and Olsvik, P. A. (2016). Exposure of first-feeding cod larvae to dispersed crude oil results in similar transcriptional and metabolic responses as food deprivation. J. Toxicol. Environ. Health A 79, 558-571. doi: 10.1080/07317131.2016.1171985

Hicken, C. E., Linbo, T. L., Baldwin, D. H., Willis, M. L., Myers, M. S., Holland, L., et al. (2011). Sublethal exposure to crude oil during embryonic development alters cardiac morphology and reduces aerobic capacity in adult fish. Proc. Natl. Acad. Sci. U.S.A. 108, 7086-7090. doi: 10.1073/pnas.1019031108

Hodson, P. V. (2017). The toxicity to fish embryos of PAH in crude and refined oils. Arch. Environ. Contam. Toxicol. 73, 12-18. doi: 10.1007/s00244-016-0357-6

Hoegberg, P., Schmidt, C. K., Nau, H., Ross, A. C., Zolfaghari, R., Fletcher, N., et al. (2003). 2,3,7,8-tetrachlorodibenzo-p-dioxin induces lecithin: retinol acyltransferase transcription in the rat kidney. Chem. Biol. Interact. 145, 1-16. doi: 10.1016/s0009-2797(02)00157-6

Incardona, J. P., Carls, M. G., Day, H. L., Sloan, C. A., Bolton, J. L., Collier, T. K., et al. (2009). Cardiac arrhythmia is the primary response of embryonic pacific herring (Clupea pallasi) exposed to crude oil during weathering. Environ. Sci. Technol. 43, 201-207. doi: 10.1021/es802270t

Incardona, J. P., Collier, T. K., and Scholz, N. L. (2004). Defects in cardiac function precede morphological abnormalities in fish embryos exposed to polycyclic aromatic hydrocarbons. Toxicol. Appl. Pharmacol. 196, 191-205. doi: 10.1016/ j.taap.2003.11.026

Incardona, J. P., Gardner, L. D., Linbo, T. L., Brown, T. L., Esbaugh, A. J., Mager, E. M., et al. (2014). Deepwater horizon crude oil impacts the developing hearts of large predatory pelagic fish. Proc. Natl. Acad. Sci. U.S.A. 111, E1510-E1518. doi: 10.1073/pnas.1320950111

Incardona, J. P., Swarts, T. L., Edmunds, R. C., Linbo, T. L., Aquilina-Beck, A., Sloan, C. A., et al. (2013). Exxon valdez to deepwater horizon: comparable toxicity of both crude oils to fish early life stages. Aquat. Toxicol. 142, 303-316. doi: 10.1016/j.aquatox.2013.08.011

Isken, A., Golczak, M., Oberhauser, V., Hunzelmann, S., Driever, W., Imanishi, Y., et al. (2008). RBP4 disrupts vitamin A uptake homeostasis in a STRA6-deficient animal model for Matthew-Wood syndrome. Cell Metabab. 7, 258-268. doi: 10.1016/j.cmet.2008.01.009

Karlsen, O., Van Der Meeren, T., Ronnestad, I., Mangor-Jensen, A., Galloway, T. F., Kjorsvik, E., et al. (2015). Copepods enhance nutritional status, growth and development in Atlantic cod (Gadus morhua L.) larvae can we identify the underlying factors?. PeerJ 3:e902. doi: 10.7717/pee rj.902

Kiser, P. D., Golczak, M., Maeda, A., and Palczewski, K. (2012). Key enzymes of the retinoid (visual) cycle in vertebrate retina. Biochim. Biophys. Acta 1821, 137-151. doi: 10.1016/j.bbalip.2011.03.005

Langmead, B., Trapnell, C., Pop, M., and Salzberg, S. L. (2009). Ultrafast and memory-efficient alignment of short DNA sequences to the human genome. Genome Biol. 10:R25. doi: 10.1186/gb-2009-10-3-r25

Laue, K., Janicke, M., Plaster, N., Sonntag, C., and Hammerschmidt, M. (2008). Restriction of retinoic acid activity by Cyp26b1 is required for proper timing and patterning of osteogenesis during zebrafish development. Development 135, 3775-3787. doi: 10.1242/dev.021238

Le, H. G. T., Dowling, J. E., and Cameron, D. J. (2012). Early retinoic acid deprivation in developing zebrafish results in microphthalmia. Vis. Neurosci. 29, 219-228. doi: 10.1017/s0952523812000296

Li, H., Handsaker, B., Wysoker, A., Fennell, T., Ruan, J., Homer, N., et al. (2009). The sequence alignment/Map format and SAMtools. Bioinformatics 25, 20782079. doi: 10.1093/bioinformatics/btp352

Lie, K. K., and Moren, M. (2012). Retinoic acid induces two osteocalcin isoforms and inhibits markers of osteoclast activity in Atlantic cod (Gadus morhua) ex vivo cultured craniofacial tissues. Comp. Biochem. Physiol. A Mol. Integr. Physiol. 161, 174-184. doi: 10.1016/j.cbpa.2011.10.023

Lobo, G. P., Hessel, S., Eichinger, A., Noy, N., Moise, A. R., Wyss, A., et al. (2010). ISX is a retinoic acid-sensitive gatekeeper that controls intestinal beta,betacarotene absorption and vitamin A production. FASEB J. 24, 1656-1666. doi: 10.1096/fj.09-150995

Lubzens, E., Lissauer, L., Levavi-Sivan, B., Avarre, J. C., and Sammar, M. (2003). Carotenoid and retinoid transport to fish oocytes and eggs: what is the role of retinol binding protein? Mol. Aspects Med. 24, 441-457. doi: 10.1016/s00982997(03)00040-2
Mazurais, D., Darias, M. J., Gouillou-Coustans, M. F., Le Gall, M. M., Huelvan, C., Desbruyeres, E., et al. (2008). Dietary vitamin mix levels influence the ossification process in European sea bass (Dicentrarchus labrax) larvae. Am. J. Physiol. Regul. Integr. Comp. Physiol. 294, R520-R527.

Mazurais, D., Glynatsi, N., Darias, M. J., Christodoulopoulou, S., Cahu, C. L., Zambonino-Infante, J. L., et al. (2009). Optimal levels of dietary vitamin A for reduced deformity incidence during development of European sea bass larvae (Dicentrarchus labrax) depend on malformation type. Aquaculture 294, 262-270. doi: 10.1016/j.aquaculture.2009. 06.008

Murphy, K. A., Quadro, L., and White, L. A. (2007). The intersection between the aryl hydrocarbon receptor (AhR)- and retinoic acid-signaling pathways. Vitam. Horm. 75, 33-67. doi: 10.1016/s0083-6729(06)75002-6

Napoli, J. L. (2016). "Function of intracellular retinoid binding proteins," in The Biochemistry of Retinoid Signaling II: The Physiology of Vitamin A uptake, Transport, Metabolism and Signaling, eds M. A. Asson-Batres and C. RochetteEgly (Dordrecht: Springer Nature), 31-76.

Niederreither, K., Vermot, J., Schuhbaur, B., Chambon, P., and Dolle, P. (2002). Embryonic retinoic acid synthesis is required for forelimb growth and anteroposterior patterning in the mouse. Development 129, 3563-3574.

Norcross, B. L., Hose, J. E., Frandsen, M., and Brown, E. D. (1996). Distribution, abundance, morphological condition, and cytogenetic abnormalities of larval herring in Prince William Sound, Alaska, following the Exxon Valdez oil spill. Can. J. Fish. Aquat. Sci. 53, 2376-2387. doi: 10.1139/f96-212

Nordtug, T., Olsen, A. J., Altin, D., Meier, S., Overrein, I., Hansen, B. H., et al. (2011). Method for generating parameterized ecotoxicity data of dispersed oil for use in environmental modelling. Mar. Poll. Bull. 62, 2106-2113. doi: 10. 1016/j.marpolbul.2011.07.015

Novák, J., Benísek, M., and Hilscherová, K. (2008). Disruption of retinoid transport, metabolism and signaling by environmental pollutants. Environ. Int. 34, 898-913. doi: 10.1016/j.envint.2007.12.024

Novák, J., Benísek, M., Pachernik, J., Janosek, J., Sidlova, T., Kiviranta, H., et al. (2007). Interference of contaminated sediment extracts and environmental pollutants with retinoid signaling. Environ. Toxicol. Chem. 26, 1591-1599.

Olsvik, P., Lie, K., Nordtug, T., and Hansen, B. (2012). Is chemically dispersed oil more toxic to Atlantic cod (Gadus morhua) larvae than mechanically dispersed oil? A transcriptional evaluation. BMC Genomics 13:702. doi: 10.1186/14712164-13-702

Pan, J., and Baker, K. M. (2007). Retinoic acid and the heart. Vitam. Horm. 75, 257-283.

Ross, S. A., Mccaffery, P. J., Drager, U. C., and De Luca, L. M. (2000). Retinoids in embryonal development. Physiol. Rev. 80, 1021-1054. doi: 10.1152/physrev. 2000.80.3.1021

Rydeen, A. B., and Waxman, J. S. (2014). Cyp26 enzymes are required to balance the cardiac and vascular lineages within the anterior lateral plate mesoderm. Development 141, 1638-1648. doi: 10.1242/dev.105874

Saari, J. C. (2016). "Vitamin A and Vision," in The Biochemistry of Retinoid Signaling II - The Physiology of Vitamin A Uptake, Transport, Metabolism and Signaling, eds M. A. Asson-Batres and C. Rochette-Egly (Dordrecht: Springer), 231-251.

Shabtai, Y., Bendelac, L., Jubran, H., Hirschberg, J., and Fainsod, A. (2018). Acetaldehyde inhibits retinoic acid biosynthesis to mediate alcohol teratogenicity. Sci. Rep. 8:347. doi: 10.1038/s41598-017-18719-7

Sorhus, E., Incardona, J. P., Furmanek, T., Goetz, G. W., Scholz, N. L., Meier, S., et al. (2017). Novel adverse outcome pathways revealed by chemical genetics in a developing marine fish. eLife 6:e20707. doi: 10.7554/eLife.20707

Sorhus, E., Incardona, J. P., Furmanek, T., Jentoft, S., Meier, S., and Edvardsen, R. B. (2016a). Developmental transcriptomics in Atlantic haddock: illuminating pattern formation and organogenesis in non-model vertebrates. Dev. Biol. 411, 301-313. doi: 10.1016/j.ydbio.2016.02.012

Sorhus, E., Incardona, J. P., Karlsen, O., Linbo, T., Sorensen, L., Nordtug, T., et al. (2016b). Crude oil exposures reveal roles for intracellular calcium cycling in haddock craniofacial and cardiac development. Sci. Rep. 6:31058. doi: 10.1038/ srep31058

Spoorendonk, K. M., Peterson-Maduro, J., Renn, J., Trowe, T., Kranenbarg, S., Winkler, C., et al. (2008). Retinoic acid and Cyp26b1 are critical regulators of osteogenesis in the axial skeleton. Development 135, 3765-3774. doi: 10.1242/ dev.024034 
Star, B., Nederbragt, A. J., Jentoft, S., Grimholt, U., Malmstrom, M., Gregers, T. F., et al. (2011). The genome sequence of Atlantic cod reveals a unique immune system. Nature 477, 207-210. doi: 10.1038/nature10342

Strate, I., Min, T. H., Iliev, D., and Pera, E. M. (2009). Retinol dehydrogenase 10 is a feedback regulator of retinoic acid signalling during axis formation and patterning of the central nervous system. Development 136, 461-472. doi: 10.1242/dev.024901

Takeuchi, T., Dedi, J., Haga, Y., Seikai, T., and Watanabe, T. (1998). Effect of vitamin A compounds on bone deformity in larval Japanese flounder (Paralichthys olivaceus). Aquaculture 169, 155-165. doi: 10.1016/s00448486(98)00373-1

Thatcher, J. E., and Isoherranen, N. (2009). The role of CYP26 enzymes in retinoic acid clearance. Expert. Opin. Drug Metab. Toxicol. 5, 875-886. doi: 10.1517/ 17425250903032681

Topletz, A. R., Tripathy, S., Foti, R. S., Shimshoni, J. A., Nelson, W. L., and Isoherranen, N. (2015). Induction of CYP26A1 by metabolites of retinoic acid: evidence that CYP26A1 is an important enzyme in the elimination of active retinoids. Mol. Pharm. 87, 430-441. doi: 10.1124/mol.114.096784

van der Meeren, T., Karlsen, O., Liebig, P. L., and Mangor-Jensen, A. (2014). Copepod production in a saltwater pond system: a reliable method for achievement of natural prey in start-feeding of marine fish larvae. Aquacult. Eng. 62, 17-27. doi: 10.1016/j.aquaeng.2014.07.003
White, R. J., and Schilling, T. F. (2008). How degrading: Cyp26s in hindbrain development. Dev. Dyn. 237, 2775-2790. doi: 10.1002/dvdy. 21695

White, T., Lu, T., Metlapally, R., Katowitz, J., Kherani, F., Wang, T. Y., et al. (2008). Identification of STRA6 and SKI sequence variants in patients with anophthalmia/microphthalmia. Mol. Vis. 14, 2458-2465.

Widerak, M., Ghoneim, C., Dumontier, M. F., Quesne, M., Corvol, M. T., and Savouret, J. F. (2006). The aryl hydrocarbon receptor activates the retinoic acid receptor alpha through SMRT antagonism. Biochimie 88, 387-397. doi: 10.1016/j.biochi.2005.11.007

Conflict of Interest Statement: The authors declare that the research was conducted in the absence of any commercial or financial relationships that could be construed as a potential conflict of interest.

Copyright (c) 2019 Lie, Meier, Sørhus, Edvardsen, Karlsen and Olsvik. This is an open-access article distributed under the terms of the Creative Commons Attribution License (CC BY). The use, distribution or reproduction in other forums is permitted, provided the original author(s) and the copyright owner(s) are credited and that the original publication in this journal is cited, in accordance with accepted academic practice. No use, distribution or reproduction is permitted which does not comply with these terms. 